\title{
Scabies, Boring Skin and Psyche
}

\section{A Situation Report}

\author{
H. Beltraminelli ${ }^{a} \quad$ A.F. Widmer ${ }^{b} \quad$ X. Jordan ${ }^{c} \quad$ C. Strub ${ }^{a} \quad$ A.J. Bircher ${ }^{a}$ \\ R. De Lorenzo ${ }^{a} \quad$ R. Herold ${ }^{b} \quad$ H. Schuhmacher ${ }^{b} \quad$ M. Buehlmann ${ }^{b} \quad$ P. Itin $^{a}$ \\ Departments of ${ }^{\mathrm{a}}$ Dermatology and ${ }^{\mathrm{b}}$ Infectious Diseases and Hospital Epidemiology, University Hospital, and

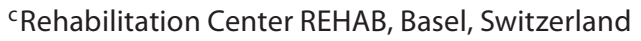

Scabies, the parasitic infestation of the skin surface caused by the mite Sarcoptes scabiei var. hominis (fig. 1) has been referred to for thousands of years (Aristotele, the Old Testament), and it continues to bother human beings. The last human scabies mite will likely to die together with the last human being.

At the first glance, scabies is a harmless and common disease transmitted by close skin contact in children, and is considered as a sexually transmitted disease among the adult population. However, scabies very frequently triggers bacterial skin infections in the developing world. The infectious agent is ubiquitous; it is endemic in some poor tropical and subtropical areas as well as in selected communities, and it is sporadic in industrialized countries. Risk factors are war, poverty, overcrowding, poor nutritional status, dementia and poor hygiene. Nevertheless, scabies is not to be considered as a 'disease of the poor', as it is present in all ethnic groups, at all socioeconomic levels and at all ages [1].

The most important symptom is a generalized itch resulting from a delayed type-IV hypersensitivity reaction to the mite and its eggs, saliva and feces. Topical permethrin $5 \%$ is considered to be the drug of choice [2], being less toxic than topical lindane or systemic ivermectin. This is an important point when considering treatment of small children and pregnant women or individuals with chronic skin disease.

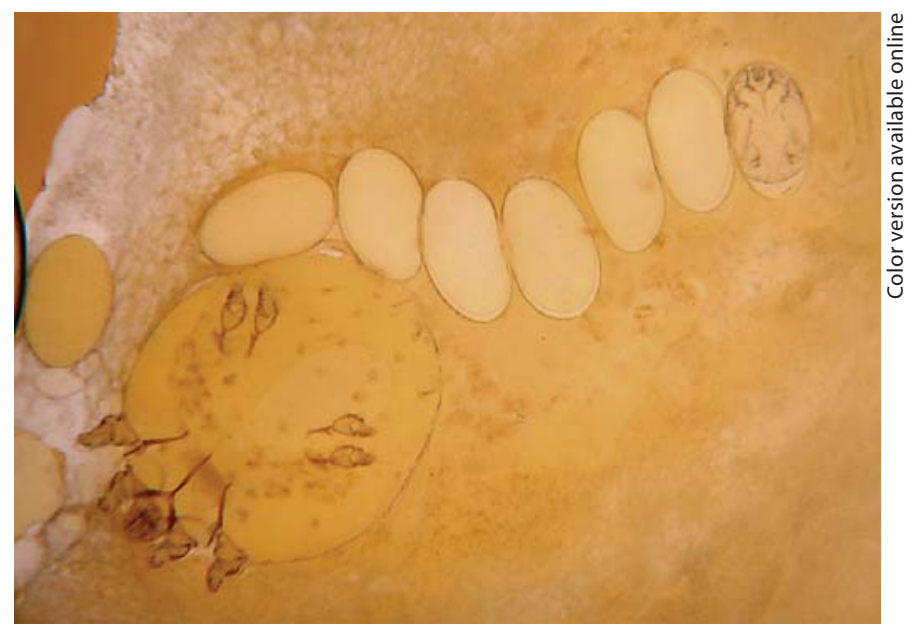

Fig. 1. Adult Sarcoptes scabiei var. homini mite with eggs.

Recently, we faced an outbreak of scabies in 2 institutions [3]: a university hospital with 750 beds and a rehabilitation facility with 92 beds. Overall 2 patients, 8 hospital co-workers (HCW) and 9 acquaintances were infested by the scabies mite (fig. 2). Tracing all the contacts (hospital, family, other occupations) of the 19 infested persons, a total of 1,661 individuals were involved, of whom 1,640 underwent preventive treatment. 


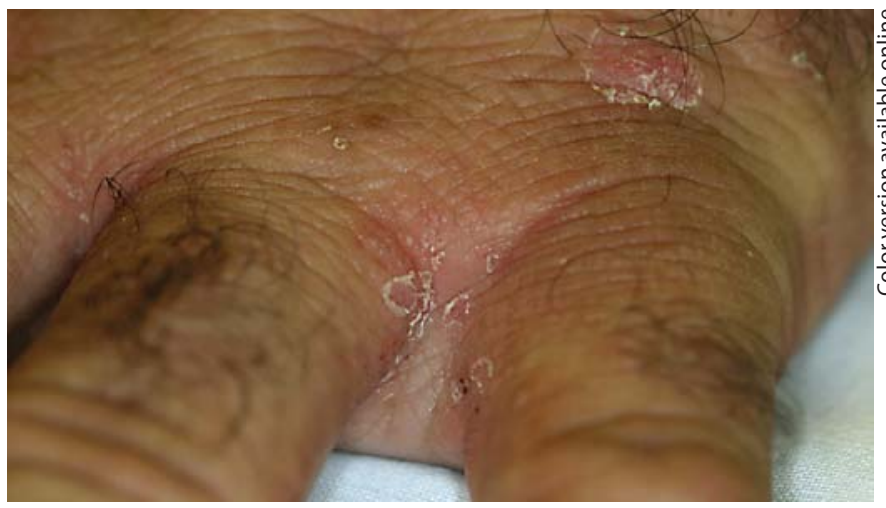

Fig. 2. Hospital coworker with infestation in a typical location, i.e. the hand.

Treatment of a scabies outbreak requires excellent management, optimal communication and extensive psychological care of the involved healthcare workers. We stress the value of a good strategy that includes: case definition (microscopically or clinically), early identification of exposed individuals (contact tracing), synchronization of the prophylactic treatment of $\mathrm{HCW}$ and of household members (to avoid any 'ping-pong effect'), coherent general guidelines for institutions and for the whole community around it. Increasing motivation of the HCW towards preventive treatment is an important point to decrease the rate of nonadherence. Defining which household members are to be prophylactically treated can be very tricky (friends of the children who are often at home, the grandparents who often take care of the children, the nanny, her boyfriend, etc.).

Even more important is the information about and around the epidemic, which should be given in various ways: regularly informing the HCW about important decisions, publishing key points on intranet of the university hospital, providing information to regional media through the spokesperson of the university hospital, giv- ing initial information to dermatologists working in private practice and general practitioners in the region. Taking into account the increasing fear (in the hospital) of the parasitosis that could be caused by such an epidemic, and considering the emotionally loaded and delicate discussions with the people involved, we opened a phone hotline to take personal questions. It is clear from analyzing the number and the content of the questions that the line was running very 'hot'.

The associated morbidity of scabies with its impact on the quality of life is frequently underestimated: considering the vexing itch, it could be exasperating from a psychological point of view; considering the psychosocial aspects, there is a sense of shame with implications for individuals and intimacy problems for couples. Moreover, a scabies outbreak in an institution is one of those stressful situations where previous conflicts easily resurface and complicate an already hectic situation. Reactions to such an epidemic can be very different: from an 'epidemic feeling of itchiness' immediately upon hearing about scabies, to hiding evident symptoms by neglecting them. However, it is important to know that HCW are still at an increased risk of acquiring scabies from patients, and that their risk is greater than that for hospitalized patients.

To manage a scabies epidemic well, some important points have to be clarified: who is paying for the medications and consultations for several thousand people, legal problems arising from using off-label treatments, legal questions about what to do with HCW who refuse prophylactic treatment, and the availability of drugs for people when considering the time and quantity available.

In conclusion, individual scabies is a harmless skin infestation, but a scabies epidemic is a serious problem [4] with significant logistic implications and relevant psychosocial consequences for individuals and for the affected community. Coherent, precise and sometimes individualized information, together with coordination of preventive treatment, are the most important points in managing such an epidemic.

\section{References}

1 Chosidow O: Clinical practices: scabies. N Engl J Med 2006;354:1718-1727.

- 2 Sunderkötter C, Mayser P, Fölster-Holst R, Maier WA, Kampen H, Hamm H: Scabies. J Dtsch Dermatol Ges 2007;5:424-430.
3 Buehlmann M, Beltraminelli H, Strub C, Bircher A, Jordan X, Battegay M, Itin P, Widmer AF: Scabies outbreak in an intensive care unit with 1,659 exposed individuals - key factors for controlling the outbreak. Infect Control Hosp Epidemiol 2009, in press.

4 Vorou R, Remoudaki HD, Maltezou HC: Nosocomial scabies. J Hosp Infect 2007;65: 9-14. 